\title{
Role of terminal and anastomotic circulation in the patency of arteries jailed by flow-diverting stents: from hemodynamic changes to ostia surface modifications
}

\author{
Christina losif, MD, MSc, PhD, ${ }^{1,2}$ Philipp Berg, PhD, ${ }^{3}$ Sebastien Ponsonnard, MD, ${ }^{4}$ \\ Pierre Carles, RE, ${ }^{5}$ Suzana Saleme, MD, ${ }^{1}$ Sanita Ponomarjova, MD,, Eduardo Pedrolo-Silveira, MD, ${ }^{1}$ \\ George A. C. Mendes, MD, ${ }^{1}$ Eduardo Waihrich, MD,, Gilles Trolliard, PhD, ${ }^{5}$ \\ Claude-Yves Couquet, DVM, ${ }^{6}$ Catherine Yardin, MD, PhD, ${ }^{2,7}$ and Charbel Mounayer, MD, PhD ${ }^{1,2}$
}

Departments of ${ }^{1}$ Interventional Neuroradiology and ${ }^{4}$ Anesthesiology, Dupuytren University Hospital (CHU Limoges); ${ }^{2} \mathrm{Applied}$ Medical Research Team and ${ }^{5}$ Science of Ceramic Processes and Surface Treatments, CNRS, UMR 7315, European Ceramic Center, University of Limoges; ${ }^{6}$ Research and Analysis Laboratory, Haute-Vienne; ' Department of Histology, Cytology, Cellular Biology, and Cytogenetics, Mother and Child (HME) University Hospital, Limoges, France; and ' ${ }^{2}$ aboratory of Fluid Dynamics and Technical Flows, University of Magdeburg "Otto von Guerike," Magdeburg, Germany

\begin{abstract}
OBJECTIVE The outcome for jailing arterial branches that emerge near intracranial aneurysms during flow-diverting stent (FDS) deployment remains controversial. In this animal study, the authors aimed to elucidate the role of collateral supply with regard to the hemodynamic changes and neointimal modifications that occur from jailing arteries with FDSs. To serve this purpose, the authors sought to quantify 1) the hemodynamic changes that occur at the jailed arterial branches immediately after stent placement and 2) the ostia surface values at 3 months after stenting; both parameters were investigated in the presence or absence of collateral arterial flow.
\end{abstract}

METHODS After an a priori power analysis, 2 groups (Group A and Group B) were created according to an animal flow model for terminal and anastomotic arterial circulation; each group contained 7 Large White swine. Group A animals possessed an anastomotic-type arterial configuration to supply the territory of the right ascending pharyngeal artery (APhA), while Group B animals possessed a terminal-type arterial configuration to supply the right APhA territory. Subsequently, all animals underwent FDS placement, thereby jailing the right APhAs. Mean flow rates and velocities inside the jailed branches were quantified using time-resolved 3D phase-contrast MR angiography before and after stenting. Three months after stent placement, the jailed ostia surface values were quantified on scanning electron micrographs. The data were analyzed using descriptive statistics and group comparisons with parametric and nonparametric tests.

RESULTS The endovascular procedures were feasible, and there were no findings of in situ thrombus formation on postprocedural optical coherence tomography or ischemia on postprocedural diffusion-weighted imaging. In Group A, the mean flow rate values at the jailed right APhAs were reduced immediately following stent placement as compared with values obtained before stent placement $(p=0.02$, power: 0.8$)$. In contrast, the mean poststenting flow rates for Group $B$ remained similar to those obtained before stent placement. Three months after stent placement, the mean ostia surface values were significantly higher for Group B $\left(527,911 \pm 306,229 \mu \mathrm{m}^{2}\right)$ than for Group A $\left(89,329 \pm 59,762 \mu \mathrm{m}^{2}\right.$; $p<0.01$, power: 1.00 ), even though the initial dimensions of the jailed ostia were similar between groups. A statistically significant correlation was found between groups (A or B), mean flow rates after stent placement, and ostia surface values at 3 months.

CONCLUSIONS When an important collateral supply was present, the jailing of side arteries with flow diverters resulted in an immediate and significant reduction in the flow rate inside these arteries as compared with the prestenting values. In contrast, when competitive flow was absent, jailing did not result in significant flow rate reductions inside the jailed

\footnotetext{
ABBREVIATIONS $3 \mathrm{DRA}=3 \mathrm{D}$ rotational angiography; $\mathrm{APhA}=$ ascending pharyngeal artery; $\mathrm{CCA}=$ common carotid artery; $\mathrm{CFD}=$ computational fluid dynamics; $\mathrm{DSA}=$ digital subtraction angiography; ECA = external carotid artery; FDS = flow-diverting stent; $M C A$ = middle cerebral artery; OCT = optical coherence tomography; $p C M R A=$ phase-contrast MR angiography; RM = rete mirabile; ROI = region of interest; SEM = scanning electron microscopy; SSS = stent shear stress.

SUBMITTED September 17, 2015. ACCEPTED February 18, 2016.
}

INCLUDE WHEN CITING Published online May 20, 2016; DOI: 10.3171/2016.2.JNS152120. 
arteries. Ostium surface values at 3 months after stent placement were significantly higher in the terminal group of jailed arteries (Group B) than in the anastomotic group (Group A) and strongly correlated with poststenting reductions in the velocity value.

https://thejns.org/doi/abs/10.3171/2016.2.JNS152120

KEY WORDS flow-diverting stent; collateral arteries; endothelialization; ostium; embolization; MR angiography; MRI; interventional neurosurgery

$\mathrm{F}$ LOW-DIVERTING stents (FDSs) ${ }^{20}$ have emerged as a new generation of endoluminal implants and have proven to be useful in the treatment of intracranial aneurysms with complex, technically challenging anatomical configurations. ${ }^{1}$ Their relatively simple placement technique and their ability to provide stable angiographic aneurysm occlusion have led to an increasing tendency towards their off-label use at distal intracranial locations. ${ }^{7}$

At the same time, controversy exists over the use of FDSs in clinical practice, ${ }^{4}$ particularly with regard to patency within the jailed arterial branch. Initial animal studies have shown that jailed branches remain patent, ${ }^{10}$ even with increased metal coverage ${ }^{16}$ or when FDSs are positioned in a telescopic fashion. ${ }^{8}$ Nevertheless, those previous studies did not focus on providing evidence for procedure-related asymptomatic branch occlusions or delayed, transient, or permanent symptoms ${ }^{13,18}$ in patients treated with FDSs.

Clinical observations ${ }^{18,29}$ of intracranial arteries jailed by FDSs generally support the hypothesis that terminal or anastomotic circulation plays a role in the patency or occlusion of jailed branches, likely attributable to the different hemodynamic modifications inside the jailed branches, ${ }^{28}$ a significant reduction in flow rate seems to trigger endothelial proliferation on the jailed ostia.

A preliminary study conducted by our group evaluated an animal model of terminal and anastomotic arterial flow at the level of Large Swine ascending pharyngeal arteries (APhAs) and yielded results that we believe require further exploration. By exploiting the flow model used in our preliminary study, we sought to compare the hemodynamic and anatomopathological consequences of jailing arterial branches in the presence or absence of collateral flow. The jailed arteries in our model had diameters ranging from 1.5 to $2.5 \mathrm{~mm}$, simulating intracranial arterial bifurcations.

Dedicated swine models of anastomotic and terminal circulation were created to simulate the presence or absence of flow competition. Time-resolved 3D phase-contrast MR angiography data (pcMRA) were postprocessed to extract time-dependent flow rate and velocity values before and after placement of the stent. For each jailed arterial branch, scanning electron microscopy (SEM) images were used to quantify the ostia surface values at 3 months after stenting. The results were compared between the 2 groups to elucidate the effects of flow diversion on isolated jailed arterial branches.

\section{Methods}

We conducted an animal study using 14 Large White swine. The sample size was defined by an a priori power analysis with variables obtained from a preliminary study. To ensure statistical validity, the animals used in the preliminary study were not included in the current study. Animals were blindly randomized into 2 groups. Concealment of group (Group A or B) and animal identification number was constant throughout the experimental period, from randomization until euthanasia, including the statistical analysis of quantitative data.

\section{Ethical Standards and Animal Care}

The institutional ethics committee for experiments on animals approved the study and validated its adherence to the national guidelines and regulations for the care and use of laboratory animals. The study design and reporting were in accordance with the Animal Research: Reporting In Vivo Experiments (ARRIVE) guidelines. ${ }^{22}$ The animal care installations, antiaggregation protocol, and general care were identical for all animals and adhered to the European Convention for the Protection of Vertebrate Animals Used for Experimental and Other Scientific Purposes. ${ }^{25}$

\section{Anesthesia, Analgesia, Medications, Euthanasia}

Animals were premedicated with aspirin $(10 \mathrm{mg} / \mathrm{kg}$ orally) and clopidogrel (10 mg/kg orally) 48 hours prior to interventions, a regimen that was maintained throughout the 3-month follow-up period. To verify the absence of procedure-related thrombus formation, intravascular optical coherence tomography (OCT; Saint Jude Medical Inc.) was performed immediately after placement of the stent.

Endovascular procedures and MRI were performed under general anesthesia. Animals were premedicated with $20 \mathrm{mg} / \mathrm{kg}$ of ketamine and $2 \mathrm{mg} / \mathrm{kg}$ of xylazine (intramuscular) and intubated. Anesthesia was maintained with propofol and sevoflurane. Euthanasia was performed with a barbiturate overdose (390 mg sodium pentobarbital and $50 \mathrm{mg} / \mathrm{cm}^{3}$ sodium phenytoin, $0.22 \mathrm{~cm}^{3} / \mathrm{kg}$ intravenously) in anesthetized animals.

\section{Flow Model Creation}

In swine, the right and left APhAs are the major branches supplying the rete mirabile (RM) and through them, the brain. In a preliminary study, we demonstrated that endovascular embolization of the left $\mathrm{APhA}$ (using bare platinum coils) and the external carotid artery (ECA)-RM anastomotic branches (using $N$-butyl-cyanoacrylate glue; Glubran, Gem Srl) was effective in eliminating competitive flow, thus producing a terminal-type circulation in the right $\mathrm{APhA}$. Two groups were created in this manner, each containing 7 animals. 
Group A received collateral flow for the territory supplied by the right $\mathrm{APhA}$ through the patent left $\mathrm{APhA}$ and the anastomotic rami that contributed to $\mathrm{RM}$ vascularization. Flow competition for the right APhA was defined as the presence of an important, direct collateral arterial network that contributed to the supply of the RM. Group $\mathrm{B}$ was created by the vascular modifications described above, resulting in a terminal-type circulation for the right $\mathrm{APhA}$, attributable to occlusion of the left $\mathrm{APhA}$ and the anastomotic rami. This group represented the absence of flow competition, which was defined as the absence of important collateral supply for the vascular territory of the right $\mathrm{APhA}$.

\section{Endovascular Procedure Technique (FD Stenting)}

A total of 14 swine, each 3 months old with a mean weight of $23.5 \pm 1.1 \mathrm{~kg}$ (95\% CI 22.9-24.2 kg), were allocated into 2 groups (Group A and Group B) of 7 animals each. The animals in Group A were not subjected to terminal-type flow modification, while those in Group $\mathrm{B}$ underwent terminal cerebrofacial arterial modification, as described in the previous section. All procedures were performed on a biplane, flat-panel digital subtraction angiography (DSA) unit (Allura Xper FD20, Philips Healthcare). For all cases, we chose the stent size (Pipeline embolization device, Covidien-Medtronic) with a nominal common carotid artery (CCA) diameter using 3D rotational angiography reconstructions; stents were deployed to cover the right $\mathrm{APhA}$ ostium at its middle part.

In situ pressure measurements inside the right $\mathrm{APhA}$ were performed through the microcatheter (Marksman, Covidien-Medtronic) before placement of the stent $2 \mathrm{~cm}$ from the ostium. The pressure measurements were also obtained before and after stenting inside the right CCA at the level of the jailed $\mathrm{APhA}, 3 \mathrm{~cm}$ proximally and $3 \mathrm{~cm}$ distally to it.

\section{Velocity and Flow Rate Quantification}

Mean flow rates and velocities were quantified before and immediately after stenting by means of a dedicated, time-resolved 3D pcMRA protocol applied on a 3.0-T system (Achieva, Philips Healthcare). The field of view covered the whole APhA and CCA-ECA regions, extending several centimeters above and below the stent borders. The values reported for velocity and flow rate were derived from raw data postprocessing from regions of interest (ROIs) chosen at $2-3 \mathrm{~cm}$ from the origin of the right $\mathrm{APhAs}$. The reported CCA and ECA flow rate and velocity measurements corresponded to ROIs placed $2 \mathrm{~cm}$ proximally and distally from the stent borders, respectively.

\section{Computational Fluid Dynamics}

Case-specific blood flow simulations, including virtual stenting and pre- and poststenting hemodynamic simulations, were performed for each data set. The poststenting pressure inside the APhAs was calculated by a computational method using blood flow data obtained by pcMRA and in situ direct pressure measurements as boundary conditions. The pressure gradient at the stented ostium was considered to be the difference in pressure in the CCA at the level of the CCA-APhA bifurcation minus the pressure inside the APhA. Pressure gradients were compared before and after stenting for each case.

The local impact of flow on the individual struts was evaluated by computing the shear stress on the free segments of stent, which will be referred to as stent shear stress (SSS). Highly resolved volume meshes (9.5-9.7 million elements for each case) were used to characterize the local impact of flow on the individual struts. The SSS was computed by considering the velocity gradients along the implant.

\section{Optical Coherence Tomography}

An OCT imaging catheter (Dragonfly Duo, Saint Jude Medical Inc.) was used (external diameter 2.7 Fr, navigated with a 0.014-inch guidewire) through the guiding catheter to produce cross-sectional images. A motorized pullback technique was used during injection of contrast medium $(5 \mathrm{~cm}$ of pullback, with the ostium of the APhA in the center of the pullback length; contrast medium injection rate: $7 \mathrm{ml} / \mathrm{sec}$; time: 4 seconds) with an acquisition of 180 images/second. Cross-sectional and 3D images were postprocessed in a dedicated console (Ilumien Optis, Saint Jude Medical Inc.).

\section{Scanning Electron Microscopy}

The stented arteries were harvested and longitudinally opened using a previously published FDS-dedicated protocol. ${ }^{19}$ Optical microscopy (Nikon Eclipse 50i Microscope, Nikon Inc.) was employed for observing the inner and outer surfaces of the freshly harvested specimens (magnifications $\times 10$ or $\times 20$ ) to verify the presence or absence of a thrombus around the stent struts.

Inner surfaces of APhA ostia were photographed (voltage: $10-15 \mathrm{kV}$, magnifications: $\times 35$ to $\times 120$ ) with SEM (JSM-7400F scanning electron microscope, JEOL). The circulating (patent) ostium surface for each stented ostium was considered to be the sum of the ostium areas that were not covered by free segments of the stent or by neointimal formation; consequently, it corresponded to the area through which blood was able to flow for each jailed artery. Quantification of the circulating ostia surfaces was performed using open-source software (ImageJ1, NIH) and hand selection of the appropriate areas.

\section{Data Comparisons and Statistical Methods}

The sample was analyzed by descriptive statistics after verifying normality using the Kolmogorov-Smirnov test. An F-test for equal variances was performed, and based on the result, either an independent samples t-test or a Welch test was used for comparison of ordinal data; a paired samples t-test or a Wilcoxon test (Mann-Whitney U-test) was used for paired data comparisons. Group correlations were analyzed using nonparametric tests (Kruskal-Wallis test, Spearman's rho rank coefficient). All data were processed with Statistica software (StatSoft Inc.); the level of statistical significance was $\mathrm{p}<0.05$.

\section{Results}

All animals were successfully embolized. All pre-, intra-, and postoperative qualitative and quantitative data 
from DSA and MRI were successfully acquired. Uneventful postprocedural recovery, satisfactory veterinary evaluation, and normal weight-gain curves were ascertained for all animals throughout the study time span.

\section{Baseline Characteristics}

The mean diameter of the jailed APhAs was $2.16 \pm 0.31$ $\mathrm{mm}(95 \%$ CI $1.98-2.35 \mathrm{~mm}$ ) before placement of the stent (Table 1). Mean APhA and CCA diameters were similar in the 2 groups (independent samples t-test: $p=0.7$ and $p=$ 0.9 , respectively). Mean in situ arterial pressure inside the $\mathrm{APhAs}$, as measured directly by the microcatheter, was $10.04 \pm 2.03 \mathrm{kPa}(95 \% \mathrm{CI} 8.75-11.34 \mathrm{kPa})$ for the whole sample; the values were similar for Groups A and B (independent samples t-test: $\mathrm{p}=0.5$ ).

\section{Endovascular Procedures}

The vascular modification procedures, which aimed to create arterial models of terminal-type circulation in Group B animals, were feasible. Selective angiographic runs from the left CCAs confirmed the absence of RM or cerebral artery opacification for Group B animals. All stents were successfully deployed at the right CCAs, covering the right $\mathrm{APhAs}$. The stent sizes used were $4.5 \times$ $20 \mathrm{~mm}$ for $28.6 \%(\mathrm{n}=4)$ of the sample, $4.75 \times 20 \mathrm{~mm}$ for $42.9 \%(\mathrm{n}=6)$, and $5 \times 20 \mathrm{~mm}$ for $28.6 \%(\mathrm{n}=4)$, with equal repartition between the 2 groups (chi-square: 0.000 , df 2 , $\mathrm{p}=1.0000)$.

For Group A, selective DSA from the right CCAs performed immediately after stent placement showed a significant reduction in contrast-medium enhancement of the jailed APhAs (Fig. 1). In contrast, there was no change in contrast medium enhancement during the pre- and poststenting DSA runs for Group B animals (Fig. 2). Immediately after deployment of the stent, intravascular OCT controls confirmed the absence of thrombus formation in all 14 cases.

The mean pressure gradient through the stent for Group A was $0.198 \mathrm{kPa}$ before stenting and $0.361 \mathrm{kPa}$ after stenting; the corresponding values for Group B were $0.529 \mathrm{kPa}$ and $0.833 \mathrm{kPa}$. The mean pressure gradient difference before and after stenting was $0.252 \mathrm{kPa}$ for Group $\mathrm{A}$ and $0.493 \mathrm{kPa}$ for Group B; the former being almost $50 \%$ lower than the latter (Fig. 3).

\section{Velocities and Flow Rates Before and After Stenting}

Pre- and poststenting blood flow rate and velocity values were successfully obtained. The absence of diffusionweighted imaging hyperintensities was confirmed for all animals. The mean blood flow rate for the whole sample of jailed APhAs was $0.553 \pm 0.299 \mathrm{~cm}^{3} / \mathrm{sec}$ before stenting and $0.428 \pm 0.321 \mathrm{~cm}^{3} / \mathrm{sec}$ after stenting; these values were not significantly different from each other (independent samples t-test, 2-tailed probability: $\mathrm{p}=0.29$ ).

Case-averaged mean and maximal velocities for the sample before stenting were $1.46 \pm 0.73 \mathrm{~cm}^{3} / \mathrm{sec}$ and $2.08 \pm$ $0.98 \mathrm{~cm}^{3} / \mathrm{sec}$, respectively; after stenting, the same parameters measured $1.14 \pm 0.60 \mathrm{~cm}^{3} / \mathrm{sec}$ and $1.76 \pm 0.93 \mathrm{~cm}^{3} /$ sec, respectively (Table 1). While the presence of a stent did not significantly reduce flow rate and velocity values

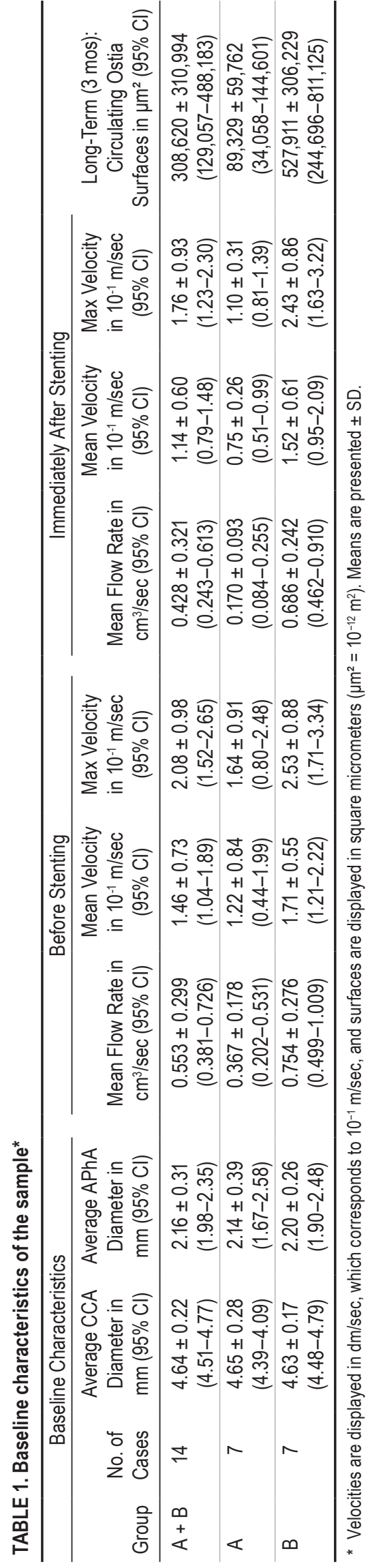

J Neurosurg Volume 126 • May 2017 

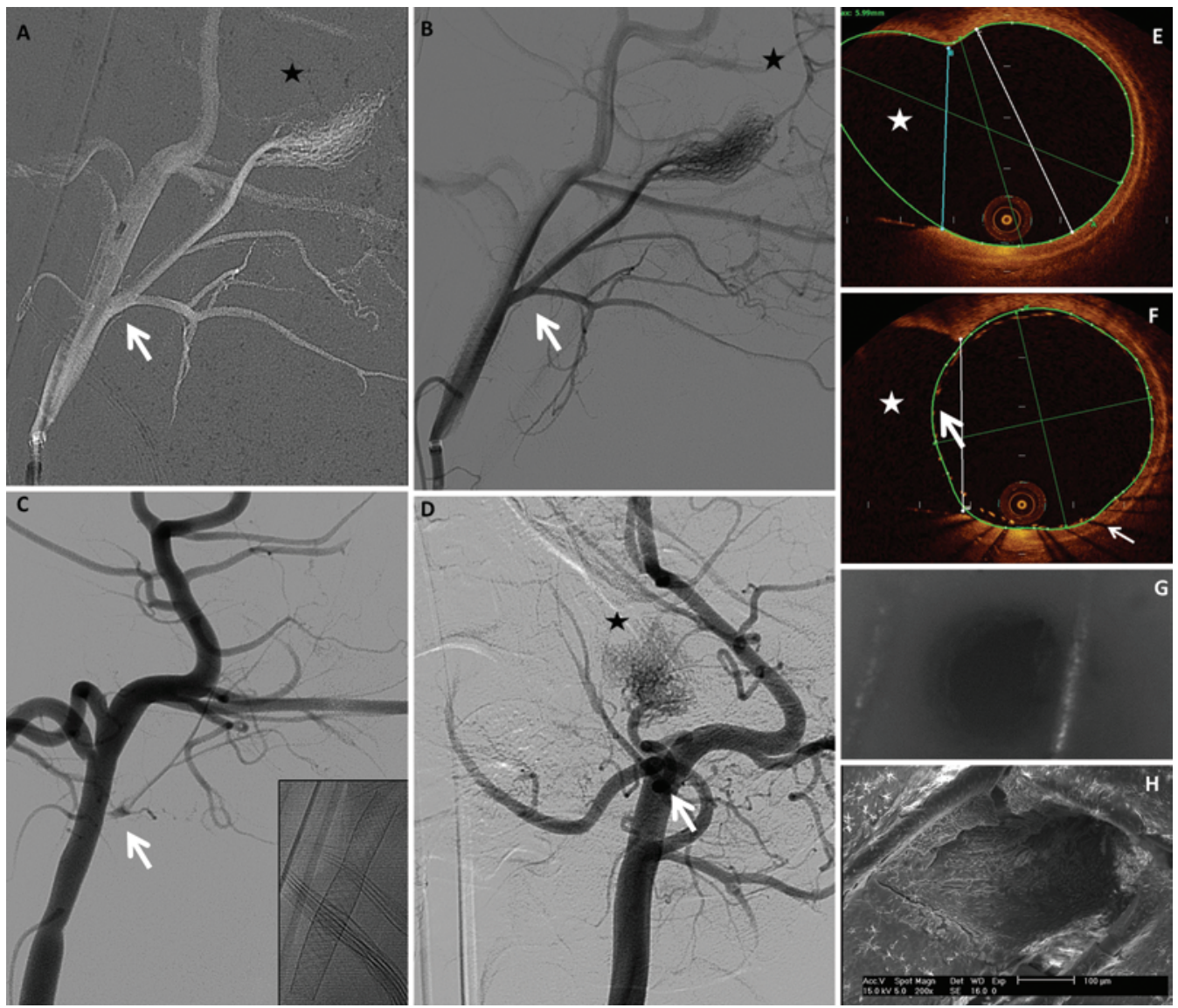

FIG. 1. Representative Group A example of anastomotic circulation. The right APhA receives flow competition from the contralateral left APhA through the RM. The mean flow rate was $0.224 \mathrm{~cm}^{3} / \mathrm{sec}$ before stenting and $0.149 \mathrm{~cm}^{3} / \mathrm{sec}$ immediately after stenting, as measured by 3D pcMRA. Panels A-D show selective DSA runs from the CCA through a 6-Fr guiding catheter. White arrows indicate the APhA-CCA bifurcation site, and black stars indicate the RM. A: Road map from the right CCA, working projection, showing the CCA-APhA bifurcation before stenting; notice the Marksman microcatheter tip at the level of the right ECA. B: Selective DSA contrast medium injection performed immediately after stenting, showing good opacification of the jailed APhA and the RM. C: Selective DSA, working projection, performed in 3-month controls, showing important remodeling of the right APhA with preocclusive aspect and the absence of opacification of the RM; the image is a single shot showing the stent, without deformation or migration. D: Selective DSA run from the left CCA, anteroposterior view, showing good opacification of the left APhA and RM. E: OCT transverse cut from the pullback run before stenting, reconstructed at the level of the right CCA-APhA bifurcation; the lumen of the right APhA (white star) is patent. F: OCT transverse cut from the pullback run immediately after stenting, reconstructed at the level of the right CCA-APhA bifurcation; the lumen of the right APhA (star) is still patent with no evidence of thrombus in situ. Notice the optical shadow created by the stent struts (thin arrow) and the stent struts of the free segment of stent (thick arrow). G: Optical microphotograph obtained in 3-month control showing the thin endothelial layer covering the stent cells. Original magnification $\times 40$. H: Scanning electron micrograph of the harvested ostium, confirming a preocclusive state; the ostium is extended only within 1 cell of the stent (circulating ostium surface at 3 months: 85,391 $\mu \mathrm{m}^{2}$; initial APhA diameter: $2.50 \mathrm{~mm}$ ). Acquisition voltage $15 \mathrm{kV}$, magnification $\times 200$. Figure is available in color online only.

for the whole sample overall, subgroup analysis revealed significant reductions in both parameters after stenting for Group A but not for Group B (as described below).

Mean flow rates for Group A were reduced from 0.367 $\mathrm{cm}^{3} / \mathrm{sec}$ before stenting to $0.17 \mathrm{~cm}^{3} / \mathrm{sec}$ after stenting; this difference was significant and statistically powerful (paired samples t-test: $\mathrm{p}=0.02$, power: 0.8 ). In contrast, mean flow rates for Group B changed from $0.754 \mathrm{~cm}^{3 /}$ sec before stenting to $0.686 \mathrm{~cm}^{3} / \mathrm{sec}$ after, a change that was not statistically significant (paired samples t-test: $p=$ $0.64)$. The prestenting flow-rate values were statistically different for the 2 groups, with Group B having higher values $(p=0.005)$ without significant statistical power; the respective poststenting values were found to be lower for Group A, with a powerful statistical difference $(\mathrm{p}=$ 0.0008, power: 0.95; Table 2).

For the whole sample, poststenting reductions in mean and maximal velocities inside the jailed arteries were not significant (independent samples t-test, 2-tailed probability: $p=0.20$ and $p=0.39$, respectively). Prestenting mean and maximal velocity values were similar for the 2 groups. For Group A, both values underwent a statistically significant reduction after stent placement as compared with the prestenting values (from $0.122 \mathrm{~m} / \mathrm{sec}$ to $0.075 \mathrm{~m} /$ sec and from $0.164 \mathrm{~m} / \mathrm{sec}$ to $0.11 \mathrm{~m} / \mathrm{sec}$, respectively; Wilcoxon's paired samples test, 2 -tailed probability: $\mathrm{p}=0.01$ ). 

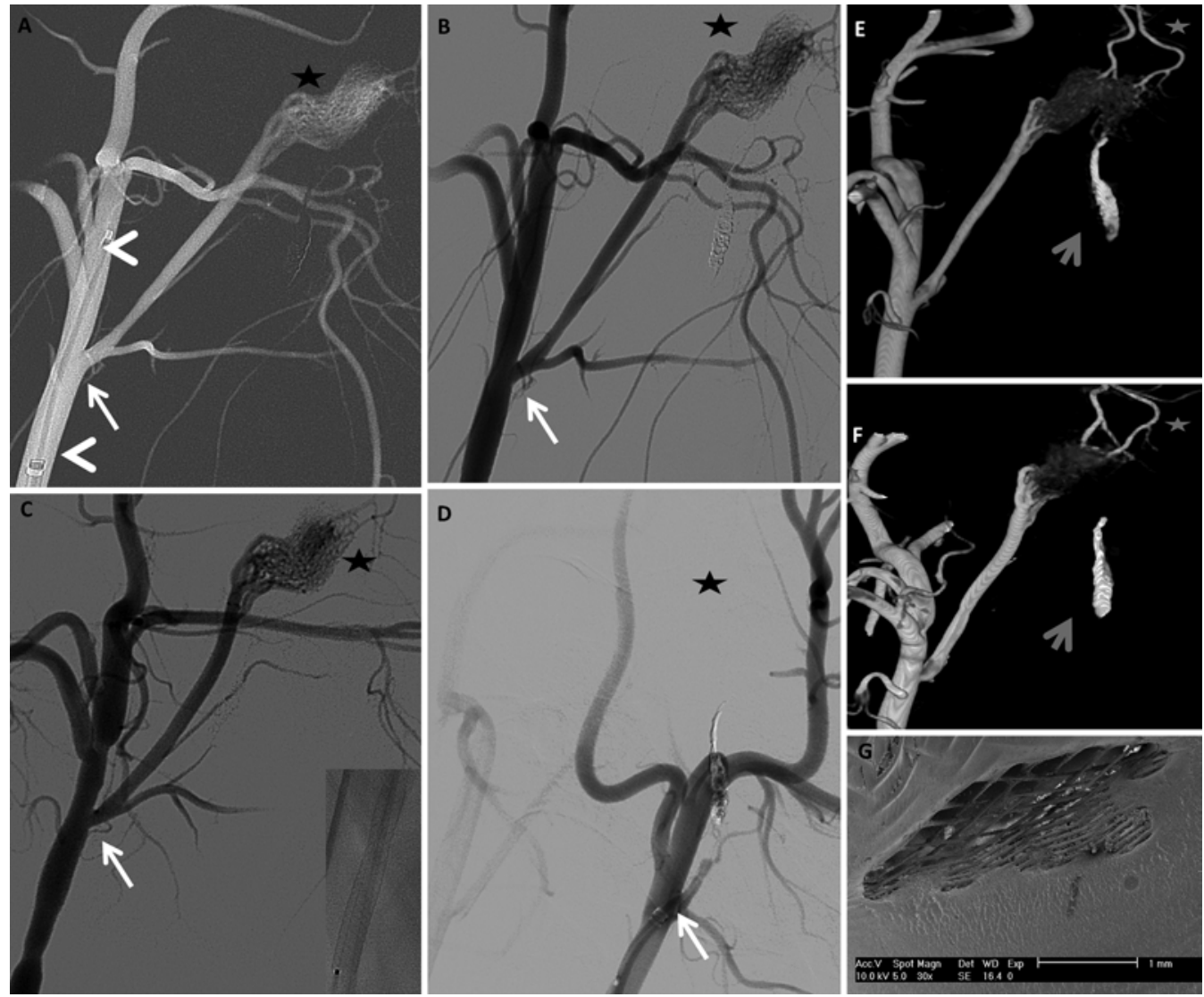

FIG. 2. Representative Group B example of terminal circulation. There is an absence of flow competition after occlusion of the left APhA and the anastomotic rami. The mean flow rate was $0.358 \mathrm{~cm}^{3} / \mathrm{sec}$ before stenting and $0.304 \mathrm{~cm}^{3} / \mathrm{sec}$ immediately after stenting, as measured by the 3D pcMRA study. Panels A-D show selective DSA runs from the CCA through the 6-Fr guiding catheter. White arrows indicate the APhA-CCA bifurcation site, and black stars indicate the RM. Road map (A) from the right CCA, working projection, showing the CCA-APhA bifurcation before stenting; notice the Marksman microcatheter at the level of the right ECA (white arrowheads). Selective DSA (B), working projection, performed immediately after stenting, showing good opacification of the jailed APhA and the RM; notice the shadow of the cast of coils that was used for occlusion of the left APhA during the flow model creation. Selective DSA (C), working projection, performed in 3-month controls, showing good patency of the right APhA without remodeling; the image is a single shot of the stent, showing no deformation or migration. Selective DSA (D) from the left CCA, showing persistent occlusion of the left APhA; the RM and swine brain are supplied by the right APhA. 3DRA reconstructions obtained before stenting $(E)$ and in 3-month controls $(F)$, showing patency of the right APhA in both cases along with significant opacification of the RM and the brain carotid arteries (equivalent to terminal internal carotid arteries in humans, gray stars) of both sides emerging from the RM; notice also the cast of coils (gray arrows) corresponding to the level of the occluded left APhA. Scanning electron micrograph $(\mathbf{G})$ of the ostium obtained at 3 months after stenting, showing a patent ostium without significant endothelial coverage of the free segments of the stent (circulating ostium surface at 3 months: $1,040,548 \mu \mathrm{m}^{2}$; initial APhA ostium diameter: $2.45 \mathrm{~mm}$ ). Acquisition voltage $10 \mathrm{kV}$, magnification $\times 30$.

In contrast, the prestenting mean and maximal velocities did not change after stenting for Group B (Wilcoxon's paired samples test, 2-tailed probability: $\mathrm{p}=0.3$ and $\mathrm{p}=$ 1.0 , respectively; Table 2).

\section{Three-Month DSA Controls}

No device displacement or deformation was observed in 3-month controls. On selective DSA runs from the right CCA, significant APhA stenoses were observed in 4 cases and near occlusion was observed in 3 cases within Group $\mathrm{A}$; no significant remodeling was found in any APhAs in Group B.

Control measurements of carotid artery diameters at the level of the ostia with 3D rotational angiography (3DRA) showed a mean diameter of $5.1 \pm 0.6 \mathrm{~mm}(95 \%$ CI $4.9-6.3$ $\mathrm{mm})$ for the right carotid arteries and $5.6 \pm 0.3 \mathrm{~mm}(95 \%$ CI 3.5-6.6 mm) for the left carotid arteries, values that were not statistically different (Welch test, $\mathrm{p}=0.2768$ ).

OCT results at 3 months after stent placement confirmed the absence of a thrombus inside all jailed APhAs and the presence of neointimal tissue on parts of the free segments of the stents, with a mean thickness of $0.13 \pm$ $0.04 \mathrm{~mm}(95 \%$ CI $0.10-0.16 \mathrm{~mm})$.

\section{Scanning Electron Microscopy Results}

At harvesting, optical microscopic images confirmed that the inner and outer ostia surfaces were clear of thrombi around the stent struts, which was consistent with OCT and DSA findings. Scanning electron micrographs were obtained, and ostia surfaces were quantified for all 


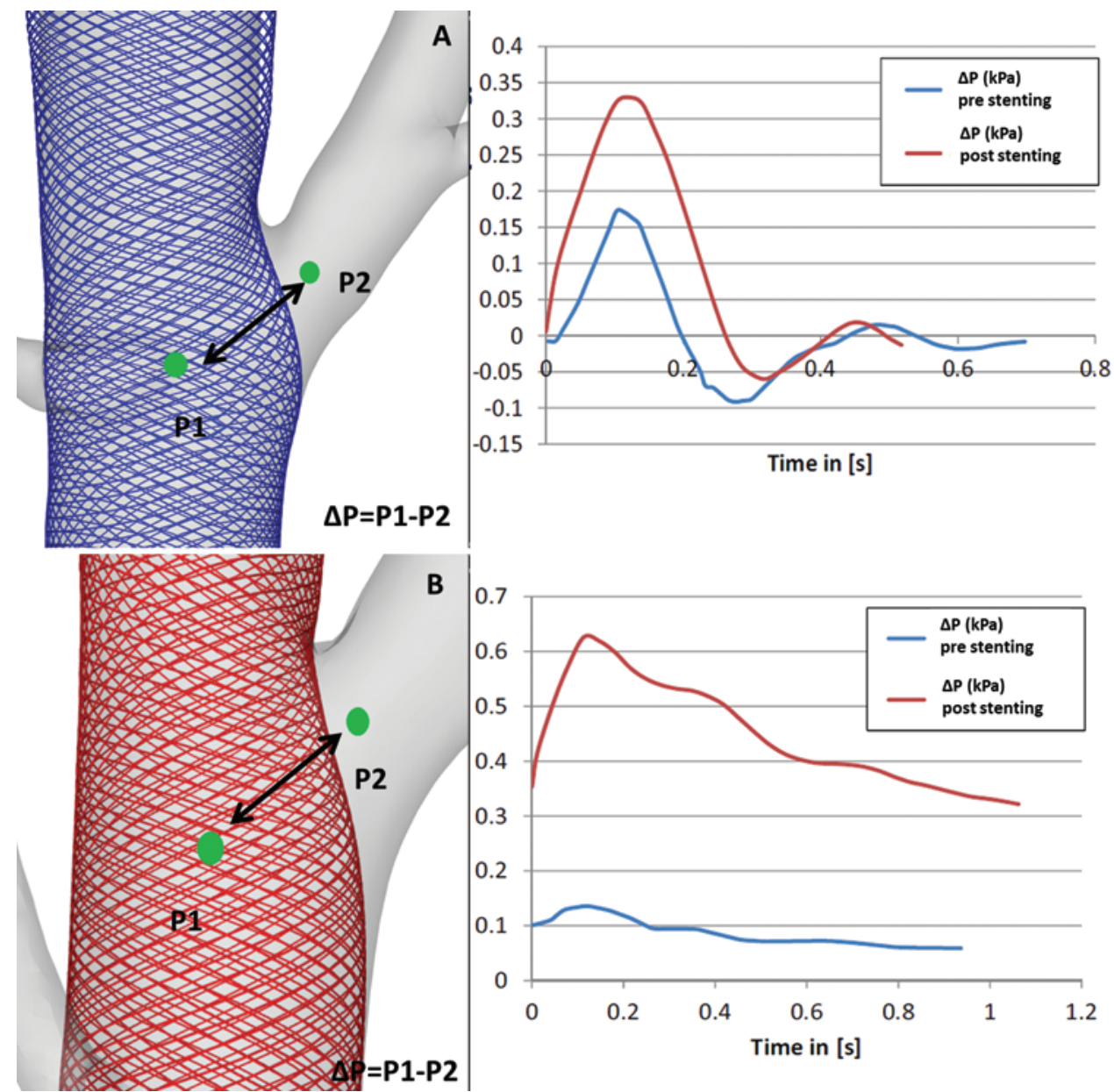

FIG. 3. Anastomotic (A, corresponds to Fig. 1) and terminal (B, corresponds to Fig. 2) circulation. Illustrations (left) are virtual stenting reconstructions showing the pressure difference (pressure gradient) $\Delta \mathrm{P}=\mathrm{P} 1-\mathrm{P} 2$. The time graphs (right) show the pressure gradient fluctuation over 1 cardiac cycle before (blue line) and after (red line) stenting. Notice the higher pressure gradient maintained after stenting for the terminal-type circulation as compared with the anastomotic type. Figure is available in color online only.

specimens. Mean circulating ostia surface (Table 1) was $308,620 \pm 310,994{\mu \mathrm{m}^{2}}^{2}\left(95 \%\right.$ CI $\left.129,057-488,183 \mu \mathrm{m}^{2}\right)$ for the whole sample, $89,329 \pm 59,762 \mu \mathrm{m}^{2}(95 \%$ CI 34,058 $144,601 \mu \mathrm{m}^{2}$ ) for Group A, and 527,911 $\pm 306,229 \mu \mathrm{m}^{2}$ (95\% CI 244,696-811,125 $\mu \mathrm{m}^{2}$ ) for Group B.

Even though $\mathrm{APhA}$ diameters were similar for the 2 groups before stenting, the mean ostium surface value at 3 months after stenting was significantly smaller for Group A (Fig. 1) than for Group B (Welch test: $p=0.0099$, power: 1.00; Fig. 2). Furthermore, nonparametric analysis of variance (by ranks) of ostia surfaces showed a statistically significant difference between the medians of the 2 groups (Kruskal-Wallis test: $p=0.0017$ ). Significant differences in hemodynamic parameters and ostia endothelialization between the 2 groups are summarized in Table 2.

All quantitative data for the Large Swine sample are presented in Table 3.

\section{Statistical Correlations and Regression Analysis}

Circulating ostium surface values at 3 months after stenting were correlated with the various hemodynamic pre- and poststenting variables (Spearman's rho coefficient); a significant correlation was found between poststenting maximal velocities and mean flow rates (r: 0.609, $\mathrm{p}=0.02$; and $\mathrm{r}: 0.635, \mathrm{p}=0.01$, respectively).

At 3 months after stent placement, multiple regression analysis showed statistically significant linear correlation of ostia surface values with the hemodynamic values and the absence of flow competition ( $\mathrm{p}=0.04$, multiple correlation coefficient: 0.9189 , coefficient of determination $\mathrm{R}^{2}$ : $0.8443, \mathrm{R}^{2}$-adjusted: 0.6627 , and residual standard deviation: 180,630.87241). Zero-order correlation coefficients showed positive statistical correlation with circulating ostia at 3 months. The regression equation retained statistically significant parameters for poststenting mean flow rates $(p=0.05)$ and for the groups $(p=0.04)$.

\section{Computational Fluid Dynamics Analysis and Comparisons}

Comparison of the virtual stent deployments with the poststenting angiographic data showed good imaging correlation. Computational fluid dynamics (CFD) results showed a poststenting reduction in flow rates and maximal 
TABLE 2. Major quantitative findings for the 2 study groups*

\begin{tabular}{|c|c|c|c|}
\hline Variable & Group A & Group B & Statistical Comparison \\
\hline $\begin{array}{l}\text { Case-averaged mean flow rate } \\
\text { before stenting in } \mathrm{cm}^{3} / \mathrm{sec}\end{array}$ & $\begin{array}{l}0.367 \pm 0.178 \\
(0.202-0.531)\end{array}$ & $\begin{array}{l}0.754 \pm 0.276 \\
(0.499-1.009)\end{array}$ & $\begin{array}{l}\text { Independent samples t-test, t: } 3.366 \text {, difference: } \\
\quad 0.4010, \text { SE: } 0.1191, \text { df: } 12, p=0.005\end{array}$ \\
\hline $\begin{array}{l}\text { Case-averaged mean flow rate } \\
\text { after stenting in } \mathrm{cm}^{3} / \mathrm{sec}\end{array}$ & $\begin{array}{r}0.170 \pm 0.093 \\
(0.084-0.255)\end{array}$ & $\begin{array}{l}0.686 \pm 0.242 \\
(0.462-0.910)\end{array}$ & $\begin{array}{l}\text { Welch test, t: } 5.270 \text {, difference: } 0.5166, \text { SE: } \\
0.09803, p=0.0008 \text {, power: } 0.95 \text { (Es: }-2.1322 \text {, } \\
\text { Type I }[\alpha]: 0.05 \text {, critical value of t: } 2.1788)\end{array}$ \\
\hline In-group comparison & $\begin{array}{l}\text { Paired samples t-test, } \\
\qquad \begin{array}{l}\mathbf{p}=\mathbf{0 . 0 2} \text {, power: } \\
0.8 \text { (Es: } 1.2187 \\
\text { Type I error }[\alpha] \text { : } \\
0.05, \text { critical value } \\
\text { of t: } 2.4469)\end{array}\end{array}$ & $\begin{array}{l}\text { Paired samples } \\
\text { t-test, } p=0.64\end{array}$ & \\
\hline $\begin{array}{l}\text { Case-averaged max velocity } \\
\text { before stenting in } \mathrm{dm} / \mathrm{sec}\end{array}$ & $\begin{array}{l}1.64 \pm 0.91 \\
(0.80-2.48)\end{array}$ & $\begin{array}{r}2.53 \pm 0.88 \\
(1.71-3.34)\end{array}$ & $\begin{array}{l}\text { Independent samples t-test: 1.860, 2-tailed prob- } \\
\quad \text { ability } p=0.09\end{array}$ \\
\hline $\begin{array}{l}\text { Case-averaged max velocity } \\
\text { after stenting in } \mathrm{dm} / \mathrm{sec}\end{array}$ & $\begin{array}{l}1.10 \pm 0.31 \\
(0.81-1.39)\end{array}$ & $\begin{array}{l}2.43 \pm 0.86 \\
(1.63-3.22)\end{array}$ & $\begin{array}{l}\text { Welch test, } t(d): 3.849,2 \text {-tailed probability } p= \\
\quad 0.004\end{array}$ \\
\hline In-group comparison & $\begin{array}{l}\text { Wilcoxon's paired } \\
\text { samples test, } \\
\text { 2-tailed probability } \\
p=0.01\end{array}$ & $\begin{array}{l}\text { Wilcoxon's paired } \\
\text { samples test, } \\
\text { 2-tailed prob- } \\
\text { ability } p=1.00\end{array}$ & \\
\hline $\begin{array}{l}\text { Case-averaged mean velocity } \\
\text { before stenting in } \mathrm{dm} / \mathrm{sec}\end{array}$ & $\begin{array}{l}1.22 \pm 0.84 \\
(0.44-1.99)\end{array}$ & $\begin{array}{l}1.71 \pm 0.55 \\
(1.21-2.22)\end{array}$ & $\begin{array}{l}\text { Independent samples t-test: 1.308, 2-tailed prob- } \\
\quad \text { ability } p=0.22\end{array}$ \\
\hline $\begin{array}{l}\text { Case-averaged mean velocity } \\
\text { after stenting in } \mathrm{dm} / \mathrm{sec}\end{array}$ & $\begin{array}{l}0.75 \pm 0.26 \\
(0.51-0.99)\end{array}$ & $\begin{array}{l}1.52 \pm 0.61 \\
(0.95-2.09)\end{array}$ & $\begin{array}{l}\text { Independent samples t-test: 3.048, 2-tailed prob- } \\
\quad \text { ability } p=0.01\end{array}$ \\
\hline In-group comparison & $\begin{array}{l}\text { Wilcoxon's paired } \\
\text { samples test, } \\
\text { 2-tailed probability } \\
p=0.01\end{array}$ & $\begin{array}{l}\text { Wilcoxon's paired } \\
\text { samples test, } \\
\text { 2-tailed probabil- } \\
\text { ity } p=0.2969\end{array}$ & \\
\hline $\begin{array}{l}\text { Mean circulating surface at } \\
3 \text { mos }\end{array}$ & $\begin{array}{c}89,329 \pm 59,762 \\
(34,058-144,601)\end{array}$ & $\begin{array}{l}527,911 \pm 306,229 \\
(244,696-811,125)\end{array}$ & 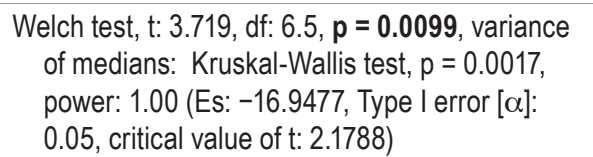 \\
\hline
\end{tabular}

Es $=$ standardized effect.

* Value $(95 \% \mathrm{Cl})$. Means are presented \pm SD. Boldface type indicates statistical significance.

velocities in the jailed arteries. In Group A animals, maximal velocities inside the APhAs decreased with the distance $(1-2 \mathrm{~cm})$ from the stent, while for Group B animals, maximal velocities seemed to be maintained regardless of the distance from the stent. In all cases, the highest SSS values occurred in the upper central areas of the covered side branches. This observation was in agreement with the ostia regions that stayed patent after 3 months. Shear stress values in Group A were lower than those observed in Group B (Fig. 4).

\section{Discussion}

Clinical, bench, and computational studies ${ }^{12,20,24}$ concerning hemodynamic changes provoked by FDSs initially focused on modifications occurring inside the aneurysm sac. Jailed arterial branches have only recently been at the center of scientific research ${ }^{14}$ partially because of an increasing tendency to be used in distal, off-label intracranial locations. Initially focused on bifurcation aneurysms, ${ }^{9}$ preclinical studies on isolated jailed branches were not ex- haustive until clinical evidence of jailed-branch occlusions with variable clinical results came to light. 2,18,26,27,29

A recent experimental study suggested that in order to significantly alter the flow rate passing through a jailed branch, proximal resistance comparable to the distal resistance needs to be created. ${ }^{6}$ According to Rouchaud et al.. ${ }^{28}$ this condition is met in human intracranial arteries when an important collateral network is present. For ethical reasons, they suggested that this hypothesis requires further confirmation by experimental animal studies. In accordance with these observations, Brinjikji et al. ${ }^{3}$ observed important, immediate poststenting flow reductions, which were persistent or increased at follow-up for almost half of their cases, in a study of jailed adult-type posterior communicating arteries during endovascular FDS treatment.

By exploiting an animal model that simulated terminal and anastomotic circulation, we noted important immediate pressure-gradient reductions in the group of jailed arteries with anastomotic circulation (Group A) that were not reproduced in the terminal circulation group (Group B), 
TABLE 3. Quantitative characteristics of the Large Swine sample

\begin{tabular}{|c|c|c|c|c|c|c|c|c|c|c|}
\hline \multicolumn{4}{|c|}{ Baseline Characteristics } & \multicolumn{3}{|c|}{ Before Stenting } & \multicolumn{3}{|c|}{ Immediately After Stenting } & \multirow[b]{2}{*}{$\begin{array}{l}\text { Long-Term } \\
\text { (3 mos): } \\
\text { Circulating } \\
\text { Ostia } \\
\text { Surfaces in } \mu \mathrm{m}^{2}\end{array}$} \\
\hline $\begin{array}{l}\text { Case } \\
\text { No. }\end{array}$ & Group & $\begin{array}{l}\text { Average } \\
\text { CCA } \\
\text { Diameter } \\
\text { in } \mathrm{mm}\end{array}$ & $\begin{array}{c}\text { Stent } \\
\text { Diameter } \\
\text { in mm }\end{array}$ & $\begin{array}{l}\text { Mean } \\
\text { Flow } \\
\text { Rate in } \\
\mathrm{cm}^{3} / \mathrm{sec}\end{array}$ & $\begin{array}{l}\text { Case-Averaged } \\
\text { Mean Velocity } \\
\text { in dm/sec }\end{array}$ & $\begin{array}{c}\text { Case-Averaged } \\
\text { Max Velocity in } \\
\text { dm/sec }\end{array}$ & $\begin{array}{l}\text { Mean } \\
\text { Flow } \\
\text { Rate in } \\
\mathrm{cm}^{3} / \mathrm{sec}\end{array}$ & $\begin{array}{l}\text { Case-Averaged } \\
\text { Mean Velocity } \\
\text { in } d m / s e c\end{array}$ & $\begin{array}{c}\text { Case-Averaged } \\
\text { Max Velocity in } \\
\text { dm/sec }\end{array}$ & \\
\hline 1 & $A$ & 4.96 & 5 & 0.445 & 1.698 & 2.556 & 0.266 & 1.234 & 1.741 & 44,045 \\
\hline 2 & $A$ & 4.23 & 4.5 & 0.177 & 0.818 & 1.121 & 0.162 & 0.804 & 1.111 & 21,507 \\
\hline 3 & $A$ & 4.43 & 4.5 & 0.474 & 2.949 & 3.232 & 0.132 & 0.705 & 0.977 & 29,440 \\
\hline 4 & A & 4.62 & 4.75 & 0.569 & 0.928 & 1.591 & 0.321 & 0.892 & 1.215 & 132,310 \\
\hline 5 & A & 4.7 & 4.75 & 0.224 & 0.702 & 0.991 & 0.149 & 0.657 & 0.942 & 85,391 \\
\hline 6 & A & 4.57 & 4.75 & 0.374 & 0.674 & 0.977 & 0.095 & 0.482 & 0.834 & 169,677 \\
\hline 7 & A & 5.05 & 5 & 0.206 & 0.74 & 0.978 & 0.062 & 0.482 & 0.874 & 142,937 \\
\hline 8 & $B$ & 4.41 & 4.5 & 0.649 & 1.387 & 2.203 & 0.669 & 2.194 & 2.766 & 873,506 \\
\hline 9 & $B$ & 4.85 & 5 & 1.098 & 2.173 & 2.543 & 1.01 & 1.782 & 2.5 & 443,023 \\
\hline 10 & $B$ & 4.56 & 4.5 & 0.844 & 1.683 & 2.839 & 0.68 & 0.76 & 1.766 & 434,906 \\
\hline 11 & B & 4.6 & 4.75 & 0.358 & 1.2 & 1.53 & 0.304 & 1.137 & 1.686 & $1,040,548$ \\
\hline 12 & B & 4.66 & 4.75 & 0.969 & 2.673 & 4.04 & 0.928 & 2.407 & 4.127 & 323,198 \\
\hline 13 & $B$ & 4.51 & 4.75 & 0.45 & 1.177 & 1.534 & 0.484 & 1.179 & 1.787 & 220,989 \\
\hline 14 & $B$ & 4.87 & 5 & 0.908 & 1.692 & 2.994 & 0.728 & 1.182 & 2.356 & 359,208 \\
\hline
\end{tabular}

providing further evidence for these recent clinical observations. Furthermore, the hemodynamic parameters (e.g., flow rates and velocities) inside the jailed arteries seemed to follow the same pattern of reduction; for the anastomotic group of arteries (Group A), important immediate flow rate and velocity value reductions were observed, while for the terminal group of arteries (Group B), significant hemodynamic reductions were absent. At the same time, the mean hemodynamic modifications after stenting were not significant for the overall population; this result is in ac- cordance with clinical studies that have reported patency of jailed branches after FDS placement, apart from isolated cases of antiaggregation treatment failures. ${ }^{1}$

In the present study, with the initiation of the flow competition concept in flow diversion animal research, we provide mechanistic evidence to explain why arteries with direct or important collateral flow, such as the anterior and posterior communicating arteries, have a tendency to occlude after FDS placement without causing symptoms, while others, such as the anterior choroidal artery ${ }^{2,27}$ or
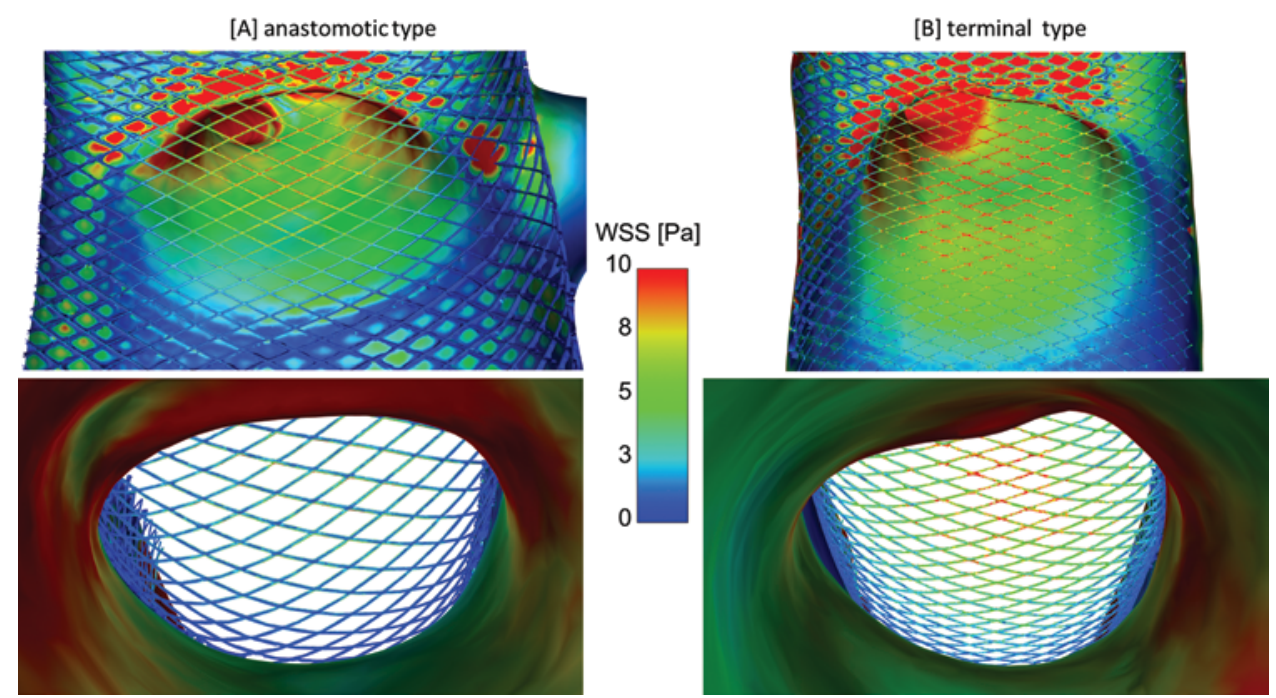

FIG. 4. Illustration of the cycle-averaged shear stresses on the vessel walls and on the stent struts for the anastomotic (left) and terminal (right) cases described in Figs. 1 and 2, respectively. Views are depicted from opposite perspectives (CCA to AphA in the upper images, and AphA to CCA in the lower images). The highest shear stress values occur in the center of the ostium and continuously decrease in each direction. The comparison of the 2 case types reveals that although similar SSS patterns are present, the cycle-averaged values differ significantly. For the stent area that is not attached to the wall, mean shear stress measured 6.7 $\mathrm{Pa}$ for the anastomotic case and 11.3 Pa for the terminal case. WSS = wall shear stress. Figure is available in color online only. 
middle cerebral artery (MCA) ${ }^{29,31,32}$ branches, tend to remain patent. Indeed, in most cases of MCA bifurcation arteries, jailed branches tend to remain patent, even when originating from the aneurysm fundus ${ }^{31}$ where one would expect that the flow reduction ${ }^{21}$ inside the aneurysm's sac would favor occlusion of the branch. The observations within this study regarding the absence of competitive flow could explain why the failure of sac occlusion was reported in some cases of aneurysms with branches arising from the sac..$^{5,11}$ When important poststenting flow rates are maintained inside the jailed artery, the common neckostium will have a tendency to remain patent.

Throughout the time course of progressive peripheral endothelialization of the common neck-ostium, flow rates will probably be subjected to modifications over time. In some cases, the simultaneous effects of progressive flow reduction and pial network development may not be sufficient for mutual counterbalance. This may explain several delayed, transient symptoms observed during the late postprocedural time in bifurcation aneurysms, especially ones located in MCA bifurcations. ${ }^{29}$ Even though the present study explored isolated jailed branches, the absence of competitive flow could be related to these observations and merits further study.

The presence or absence of a collateral supply was retained in this study as an important factor related to the degree of patency at the ostium at 3 months after stent placement. The nature (terminal or anastomotic) of an artery that is susceptible to jailing by a flow diverter was shown to have an important role in its fate with respect to patency. In accordance with recent clinical observations, ${ }^{29}$ our results suggest that the presence or absence of competitive flow within a specific artery should be taken into account before coverage of its ostium by a flow diverter. Direct anastomotic arterial configurations could indeed be helpful for rapid healing in human intracranial aneurysm treatment; on the contrary, a terminal-type arterial supply is expected to prevent significant stenosis of a jailed artery.

In the present study, all animals exhibited a degree of jailed ostium neointimal coverage, which was significantly correlated with the degree of reduction in the immediate flow rate and velocity values. The results of this study demonstrate that the poststenting reduction of the ostium surface at 3 months is dependent on flow rate and velocity values inside the jailed artery immediately after stenting. These results reinforce the hypothesis that, apart from thrombotic mechanisms, hemodynamic changes may also induce side-branch remodeling or even occlusion in effectively antiaggregated patients, even without the presence of acute thrombotic and recanalization mechanisms.

Furthermore, shear stress calculations for the anastomotic cases showed lower values at the level of the free segments of stent than those observed in the terminal circulation cases. Given that vascular cells are equipped with receptors that allow them to detect and respond to the mechanical forces generated by shear stress,${ }^{30}$ shear stress differences on the free segments of stent in terminal and anastomotic circulation may have a role in determining the extent of neointimal coverage of the ostia.

Further research on the poststenting effects of hemodynamic modifications on the mechanisms of signaling and endothelial proliferation on the free segments of the stent seems to be important in the field of intracranial flow diversion. Determining cutoffs of prestenting velocities that could be considered safe according to jailed-branch localization and the collateral supply is also an important goal of translational and clinical research in the field.

\section{Study Limitations}

The results of this study do not exclude transient or permanent neurological symptoms after jailing a terminaltype human intracranial artery. Nevertheless, this study provides a valid concept for further understanding the important role of hemodynamic factors in the fate of jailed branches and provides a new basis for further research involving experimental bifurcation aneurysms. The results of the present study apply only in cases with an effective antiaggregation regimen; otherwise, thrombotic mechanisms may produce a different outcome.

In a few human case series involving intracranial arterial perforators, ${ }^{15,23}$ rare symptomatic occlusions in jailed branches were reported. Perforators are by definition terminal arteries and, according to our observations, are expected to remain patent after stenting. A recent clinical study on intracranial perforators has shown results that further support our observations. ${ }^{23}$ Additionally, in a recent CFD study in small-caliber human arteries, ${ }^{17}$ a relatively low flow rate reduction of $8 \%$ was found after FDS jailing. In a recent animal study dealing with telescopic stenting, Dai et al. ${ }^{8}$ found patency of the jailed branches while at the same time acknowledging limitations regarding perforators.

Nevertheless, intracranial perforators represent a limitation of the present study; the study concerns jailed branches with diameters ranging from 1 to $2.3 \mathrm{~mm}$ and does not examine those with diameters less than $1 \mathrm{~mm}$. Human intracranial perforators are very small-caliber arteries that have much lower initial flow rates and probably will result in even lower flow rates after stenting. As stated by Cebral et al., "important flow reductions can be expected when the FDS covers a significant portion of the area of the orifice."

Jailing a very small ostium may result in a much higher percentage of metal coverage than expected by a commercial FDS; telescopic stenting in very narrow arteries may further accentuate this result. ${ }^{16}$ In our opinion, although human perforators are considered terminal arterial branches, their relatively long course, coupled with a very small diameter, may result in important flow rate reductions in cases of increased metal coverage, as can occur in telescopic stenting. Further research is needed to address this important issue and is currently underway.

\section{Conclusions}

This study demonstrates that the absence of collateral supply in an artery jailed by an FDS contributed to the preservation of flow rates comparable to those measured prior to stenting. In contrast, the presence of collateral supply resulted in a significant reduction in flow rate as compared with prestenting values. Important flow rate reductions immediately after stenting were strongly cor- 
related with increased neointimal coverage of the ostia at 3 months after stent placement. The absence of flow competition was correlated with significantly higher values of circulating ostia surfaces after 3 months.

\section{Acknowledgments}

We thank Marie-Jeanne Cornuejols, who was responsible for animal care in the Haute-Vienne Animal Laboratory; Mathieu Fournier and Adeline Dumas, radiographers at the CHU of Limoges; and the students of the Anesthetist's Nurse School of Limoges for their long working hours and their endless availability and support on this project. We also thank the International Max Planck Research School for Analysis, Design, and Optimization in Chemical and Biomedical Process Engineering, Magdeburg; CovidienMedtronic for providing neurovascular material; the University of Limoges, France, for providing animal acquisition and care; and the Federal Ministry of Education and Research in Germany within the Research Campus STIMULATE for financial support.

\section{References}

1. Becske T, Kallmes DF, Saatci I, McDougall CG, Szikora I, Lanzino G, et al: Pipeline for uncoilable or failed aneurysms: results from a multicenter clinical trial. Radiology 267:858868, 2013

2. Brinjikji W, Kallmes DF, Cloft HJ, Lanzino G: Patency of the anterior choroidal artery after flow-diversion treatment of internal carotid artery aneurysms. AJNR Am J Neuroradiol 36:537-541, 2015

3. Brinjikji W, Lanzino G, Cloft HJ, Kallmes DF: Patency of the posterior communicating artery after flow diversion treatment of internal carotid artery aneurysms. Clin Neurol Neurosurg 120:84-88, 2014

4. Brinjikji W, Murad MH, Lanzino G, Cloft HJ, Kallmes DF: Endovascular treatment of intracranial aneurysms with flow diverters: a meta-analysis. Stroke 44:442-447, 2013

5. Caroff J, Neki H, Mihalea C, D'Argento F, Abdel Khalek H, Ikka L, et al: Flow-diverter stents for the treatment of saccular middle cerebral artery bifurcation aneurysms. AJNR Am J Neuroradiol 37:279-284, 2016

6. Cebral JR, Raschi M, Mut F, Ding YH, Dai D, Kadirvel R, et al: Analysis of flow changes in side branches jailed by flow diverters in rabbit models. Int $\mathbf{J}$ Numer Methods Biomed Eng 30:988-999, 2014

7. Chalouhi N, Starke RM, Yang S, Bovenzi CD, Tjoumakaris $\mathrm{S}$, Hasan D, et al: Extending the indications of flow diversion to small, unruptured, saccular aneurysms of the anterior circulation. Stroke 45:54-58, 2014

8. Dai D, Ding YH, Kadirvel R, Rad AE, Lewis DA, Kallmes DF: Patency of branches after coverage with multiple telescoping flow-diverter devices: an in vivo study in rabbits. AJNR Am J Neuroradiol 33:171-174, 2012

9. Darsaut TE, Bing F, Makoyeva A, Gevry G, Salazkin I, Raymond J: Flow diversion of giant curved sidewall and bifurcation experimental aneurysms with very-low-porosity devices. World Neurosurg 82:1120-1126, 2014

10. Darsaut TE, Bing F, Salazkin I, Gevry G, Raymond J: Flow diverters can occlude aneurysms and preserve arterial branches: a new experimental model. AJNR Am J Neuroradiol 33:2004-2009, 2012

11. Darsaut TE, Bing F, Salazkin I, Gevry G, Raymond J: Flow diverters failing to occlude experimental bifurcation or curved sidewall aneurysms: an in vivo study in canines. J Neurosurg 117:37-44, 2012

12. Fiorella D, Lylyk P, Szikora I, Kelly ME, Albuquerque FC, McDougall CG, et al: Curative cerebrovascular reconstruction with the Pipeline embolization device: the emergence of definitive endovascular therapy for intracranial aneurysms. J Neurointerv Surg 1:56-65, 2009
14. Gascou G, Lobotesis K, Brunel H, Machi P, Riquelme C, Eker O, et al: Extra-aneurysmal flow modification following pipeline embolization device implantation: focus on regional branches, perforators, and the parent vessel. AJNR Am J Neuroradiol 36:725-731, 2015

15. Gawlitza M, Januel AC, Tall P, Bonneville F, Cognard C: Flow diversion treatment of complex bifurcation aneurysms beyond the circle of Willis: a single-center series with special emphasis on covered cortical branches and perforating arteries. J Neurointerv Surg [epub ahead of print], 2015

16. Hong B, Wang K, Huang Q, Xu Y, Fang X, Li Z, et al: Effects of metal coverage rate of flow diversion device on neointimal growth at side branch ostium and stented artery: an animal experiment in rabbit abdominal aorta. Neuroradiology 54:849-855, 2012

17. Hu P, Qian Y, Zhang Y, Zhang HQ, Li Y, Chong W, et al: Blood flow reduction of covered small side branches after flow diverter treatment: a computational fluid hemodynamic quantitative analysis. J Biomech 48:895-898, 2015

18. Iosif C, Camilleri Y, Saleme S, Caire F, Yardin C, Ponomarjova $S$, et al: Diffusion-weighted imaging-detected ischemic lesions associated with flow-diverting stents in intracranial aneurysms: safety, potential mechanisms, clinical outcome, and concerns. J Neurosurg 122:627-636, 2015

19. Iosif C, Carles P, Trolliard G, Yardin C, Mounayer C: Scanning electron microscopy for flow-diverting stent research: technical tips and tricks. Microscopy (Oxf) 64:219-223, 2015

20. Kallmes DF, Ding YH, Dai D, Kadirvel R, Lewis DA, Cloft HJ: A new endoluminal, flow-disrupting device for treatment of saccular aneurysms. Stroke 38:2346-2352, 2007

21. Kerl HU, Boll H, Fiebig T, Figueiredo G, Förster A, Nölte IS, et al: Implantation of pipeline flow-diverting stents reduces aneurysm inflow without relevantly affecting static intraaneurysmal pressure. Neurosurgery 74:321-334, 2014

22. Kilkenny C, Browne W, Cuthill IC, Emerson M, Altman DG: Animal research: reporting in vivo experiments-the ARRIVE guidelines. J Cereb Blood Flow Metab 31:991-993, 2011

23. Kühn AL, Hou SY, Perras M, Brooks C, Gounis MJ, Wakhloo AK, et al: Flow diverter stents for unruptured saccular anterior circulation perforating artery aneurysms: safety, efficacy, and short-term follow-up. J Neurointerv Surg 7:634-640, 2015

24. Ma D, Dargush GF, Natarajan SK, Levy EI, Siddiqui AH, Meng H: Computer modeling of deployment and mechanical expansion of neurovascular flow diverter in patient-specific intracranial aneurysms. J Biomech 45:2256-2263, 2012

25. Newcomer CE: The evolution and adoption of standards used by AAALAC. J Am Assoc Lab Anim Sci 51:293-297, 2012

26. Puffer RC, Kallmes DF, Cloft HJ, Lanzino G: Patency of the ophthalmic artery after flow diversion treatment of paraclinoid aneurysms. J Neurosurg 116:892-896, 2012

27. Raz E, Shapiro M, Becske T, Zumofen DW, Tanweer O, Potts $\mathrm{MB}$, et al: Anterior choroidal artery patency and clinical follow-up after coverage with the pipeline embolization device. AJNR Am J Neuroradiol 36:937-942, 2015

28. Rouchaud A, Leclerc O, Benayoun Y, Saleme S, Camilleri Y, D'Argento F, et al: Visual outcomes with flow-diverter stents covering the ophthalmic artery for treatment of internal carotid artery aneurysms. AJNR Am J Neuroradiol 36:330 336,2015

29. Saleme S, Iosif C, Ponomarjova S, Mendes G, Camilleri Y, Caire F, et al: Flow-diverting stents for intracranial bifurcation aneurysm treatment. Neurosurgery 75:623-631, 2014

30. Valls i Soler A, Wauer RR: 2nd European symposium on liquid ventilation. Eur J Med Res 6:115-138, 2001

31. Yavuz K, Geyik S, Saatci I, Cekirge HS: Endovascular treatment of middle cerebral artery aneurysms with flow modi- 
fication with the use of the pipeline embolization device. AJNR Am J Neuroradiol 35:529-535, 2014

32. Zanaty M, Chalouhi N, Tjoumakaris SI, Gonzalez LF, Rosenwasser R, Jabbour P: Flow diversion for complex middle cerebral artery aneurysms. Neuroradiology 56:381-387, 2014

\section{Disclosures}

Dr. Mounayer is a consultant for Covidien-Medtronic.

\section{Author Contributions}

Conception and design: Iosif, Mounayer. Acquisition of data: Iosif, Ponsonnard, Carles, Ponomarjova, Pedrolo-Silveira,

Mendes, Waihrich, Couquet. Analysis and interpretation of data: Iosif, Berg, Carles. Drafting the article: Iosif. Critically revising the article: Saleme, Trolliard, Mounayer. Reviewed submitted version of manuscript: Mounayer. Approved the final version of the manuscript on behalf of all authors: Iosif. Statistical analysis: Iosif. Study supervision: Yardin, Mounayer. CFD simulations: Berg.

\section{Supplemental Information}

Online-Only Content

Supplemental material is available with the online version of the article.

Supplementary Figure. https://thejns.org/doi/suppl/10.3171/ 2016.2.JNS152120.

\section{Correspondence}

Christina Iosif, 2 Avenue Martin Luther King, Limoges 87042, France. email: christina.iosif@gmail.com. 